\title{
Experimental Study of the Mechanism of Acid Rain-Gabbro Interaction
}

\author{
Xiaoyan Zhao ${ }^{1, *}$, Kunpeng $\mathrm{Li}^{1}$, Dian $\mathrm{Xiao}^{1}$, and Xun $\mathrm{Li}^{1}$ \\ ${ }^{1}$ Department of Geology Engineering, Southwest Jiaotong University, 610031 Chengdu Sichuan, \\ China
}

\begin{abstract}
As a common natural disaster, acid rain could not only cause serious environmental pollution, but also endanger the engineering properties of rock due to water-rock interactions. The failure of slopes of mafic igneous or ultramafic igneous rock is not unusual in areas affected by acid rain, but the specific mechanism of instability remains to be studied. In this study, fresh gabbro samples were processed, and a simulated acid rain treatment of $\mathrm{pH} 3.0$ in the laboratory was carried out. Then the shear strength parameters were evaluated on samples before and after the acid rain test. Finally, the samples were analyzed by X-ray Diffraction (XRD), Polarizing Microscope and Scanning Electron Microscope (SEM) to analyze the mechanism of acid rain-gabbro interaction. Overall, this study provided useful insights toward the evaluation of engineering properties of mafic igneous and ultramafic igneous rocks in acid rain area.
\end{abstract}

\section{Introduction}

With the rapid development of modern industrial technology and the extensive application of mineral resources such as coal and oil, south China has become the third largest region with heavy acid deposition after Europe and North America (see Fig. 1). Currently acid rain has been emphasized by the Chinese people due to its enormous threat to human health, environment and ecosystem. In addition to the hazards mentioned above, recent studies suggest that acid rain may induce or accelerate geological disasters through acid rain-rock interaction [1-4].

The mineral stability sequence, in general, coincides with Bowen's reaction series that ranked minerals in the order of crystallization from a cooling magma[5]. The major primary minerals of mafic igneous and ultramafic igneous rocks are pyroxene and calcic plagioclase which tend to crystallize at higher temperatures according to Bowen's reaction series, so that they are less chemically stable and more susceptible to the effects of acid rain compared with other minerals. Based on these characteristics, the interaction between water and mafic igneous or ultramafic igneous rocks may be intensified under the action of acid rain.

\footnotetext{
*Corresponding author:xyzhao2@swjtu.cn
} 
In this paper, gabbro samples, as typical mafic igneous rocks, were selected and processed. Then, a simulated acid rain treatment of $\mathrm{pH} 3.0$ in the laboratory was carried out. Finally X-ray Diffraction (XRD), Polarizing Microscope and Scanning Electron Microscope (SEM) were applied to analyze the mechanism of acid rain-gabbro interaction.

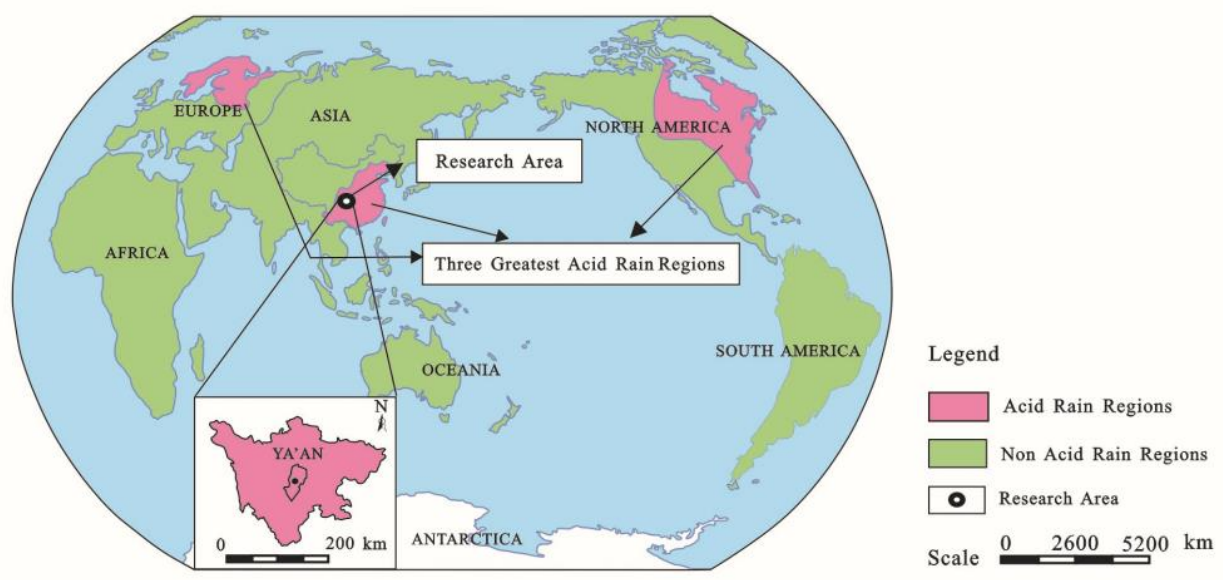

Fig. 1. Spatial distribution of acid rain in the world, and the location of the research area.

\section{Experiments of acid rain-gabbro interaction}

\subsection{Preparation of test samples}

The original gabbro samples were taken from a slope located in Ya'an city, Sichuan Province, China (typical acid rain area). All samples used in this study were cut into cylinders with $5.5 \mathrm{~cm}$ in cross-sectional diameter and $2 \mathrm{~cm}$ in high. A series of grooves cut in the top surface of cylinder simulated the actual structural plane of rocks (see Fig. 2).

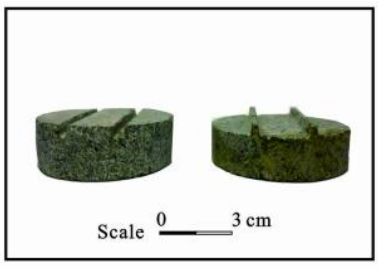

(a)

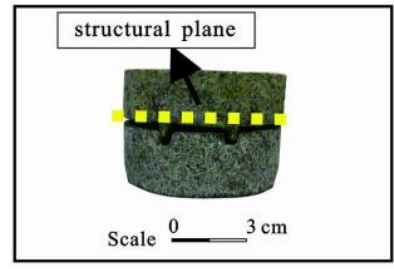

(b)

Fig 2. Cylindrical samples.

\subsection{Experiment method}

The annual average action volume of acid rain for the cylindrical sample is expressed as:

$$
V=P \times S
$$

Where $P$ is average annual rainfall, $S$ denotes the surface area of the cylindrical sample.

Based on the related data derived from the Ya'an Bureau of Meteorology, the average annual rainfall for the study region was about $777.4 \mathrm{~mm}$ with an average $\mathrm{pH}$ of 4.38 . As 
mentioned above, the cross-sectional diameter of cylindrical sample is $5.5 \mathrm{~cm}$, so the annual average action volume of acid rain obtained by Eq. (1) is about $1.85 \mathrm{~L}$.

To accelerate reaction velocity of acid rain-gabbro interaction, the cylindrical samples were treated with simulated acid rain inputs of $\mathrm{pH} 3$. According to the principle of equivalent molar quantities of hydrogen ion, the corresponding relation between the actual and simulated acid rain was calculated for 20 years and 40 years as seen in Table 1 .

Table 1. Corresponding relation between the actual and simulated acid rain.

\begin{tabular}{|c|c|c|c|c|}
\hline $\begin{array}{c}\text { Duration of } \\
\text { actual acid rain } \\
/ \mathbf{y}\end{array}$ & $\begin{array}{c}\text { Volume of } \\
\text { actual acid rain } \\
/ \mathbf{L}\end{array}$ & $\begin{array}{c}\text { Mole quantity } \\
\mathbf{o f} \mathbf{H}^{+} \\
/ \mathbf{m o l}^{\mathbf{m o l}}\end{array}$ & $\begin{array}{c}\text { Volume of } \\
\text { stimulation } \\
\text { acid rain } \\
/ \mathbf{L}\end{array}$ & $\begin{array}{c}\text { Duration of } \\
\text { stimulation acid } \\
\text { rain } \\
/ \mathbf{d}\end{array}$ \\
\hline 20 & 36.9 & $1.54 \times 10^{-3}$ & 1.54 & 7 \\
\hline 40 & 73.8 & $3.08 \times 10^{-3}$ & 3.08 & 14 \\
\hline
\end{tabular}

Based on Table 1, the average daily simulated rainfall was about $220 \mathrm{~mL}$, so the cylindrical samples were treated with $73.3 \mathrm{~mL}$ simulated rainfall three times a day. A delay between each treatment simulated the process after the stop of rainfall.

\subsection{Results of direct shear test}

YDS-1 indoor portable shear apparatus was used to conduct direct shear tests on cylindrical samples before and after the acid rain exposures. The results are shown in Fig. 3.

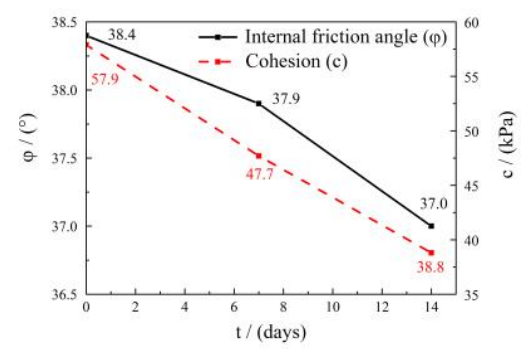

Fig 3. Curves of shear strength parameters with different durations of simulated acid rain action.

The effects of acid rain on the shear strength parameters of the samples are clear, as shown in Fig. 3. After 7 days of treatment by simulated acid rain, the internal friction angle and the cohesive force were reduced from $38.4^{\circ}$ and $57.9 \mathrm{kPa}$ to $37.9^{\circ}$ and $47.7 \mathrm{kPa}$. After 14 days, the internal friction angle and the cohesive force decreased to $37.0^{\circ}$ and $38.8 \mathrm{kPa}$.

\section{Analysis of acid rain-gabbro interaction mechanisms}

\subsection{X-ray diffraction analysis}

To analyze the mechanisms for the decrease of shear strength parameters under acid rain, $\mathrm{X}$-ray diffractometry was carried out to study the changes of mineral compositions of samples before and after the action of simulated acid rain (Fig. 4 and Table 2). 


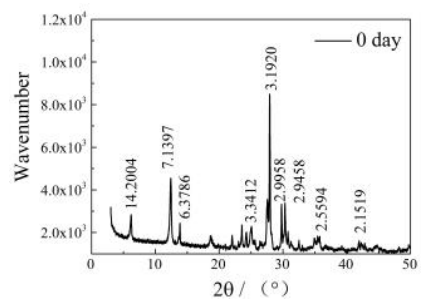

(a) 0 day

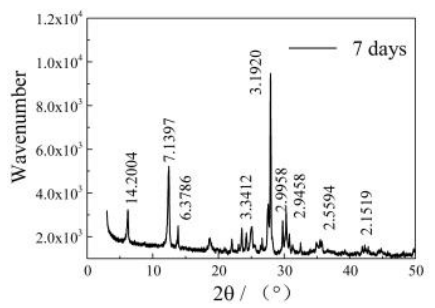

(b) 7 days

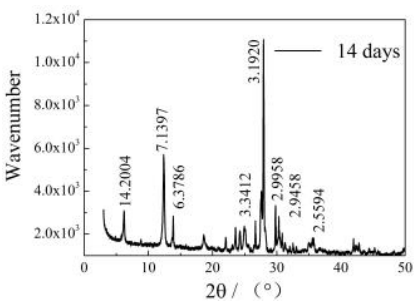

(c) 14 days

Fig. 4. X-ray diffraction pattern of the samples with different acid rain exposure times.

Table 2. Mineral contents of samples from XRD analysis.

\begin{tabular}{|c|c|c|c|c|c|c|c|}
\hline $\begin{array}{c}\text { Duration } \\
\text { of } \\
\text { simulated } \\
\text { acid rain } \\
\text { /d }\end{array}$ & Plagioclase & Pyroxene & Quartz & Chlorite & Kaolinite & Illite & Other \\
\cline { 2 - 8 } & & & & & & & \\
\hline 0 & 51.5 & 10.9 & 0.7 & 25.7 & 6.8 & 3.5 & 1.0 \\
\hline 7 & 47.5 & 9.4 & 1.0 & 26.5 & 7.2 & 7.3 & 1.0 \\
\hline 14 & 50.6 & 8.7 & 1.8 & 23.5 & 7.9 & 5.9 & 1.0 \\
\hline
\end{tabular}

Table 2 shows that the relative percentages of pyroxene and calcic plagioclase decreased after 7-day exposures to simulated acid rain, probably because pyroxene and calcic plagioclase were weathered into chlorite, illite and kaolinite under acidic conditions, accompanied with the generation of soluble salts. After 14 days, pyroxene and calcic plagioclase kept the transition mentioned above, but chlorite and illite were partly dissolved and converted into kaolinite. Part of the chain silicate mineral (pyroxene) and the framework silicate mineral (calcic plagioclase) were converted into layered silicate minerals (chlorite, illite and kaolinite) leading to a remarkable decrease of the shear strength.

\subsection{Polarizing Microscope analysis}

Polarizing Microscope analysis are shown in Fig. 5. The content of clay minerals formed from pyroxene and calcic plagioclase increased with increased duration of acid rain. The percentage of clay minerals were $33 \%, 42 \%$, and $40 \%$ with different duration of acid rain, which are comparable with the XRD results.

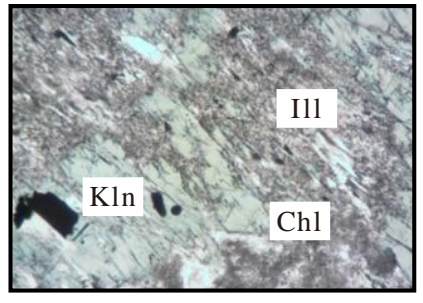

(a) 0 day

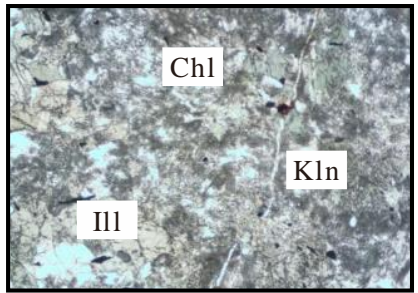

(b) 7 days

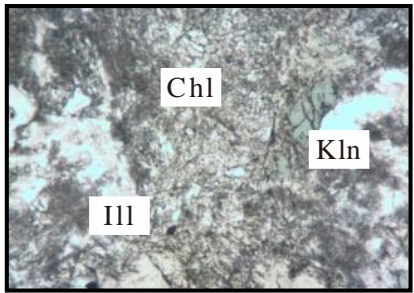

(c) 14 days

Fig.5. Photomicrographs of the samples with different durations of acid rain action. (Chl: chlorite; Kln: kaolinite; Ill: illite). 


\subsection{Scanning Electron Microscope analysis}

Scanning Electron Microscope analysis was adopted to observe micro-changes of the sample surfaces before and after the treatment of acid rain (Fig. 6.).

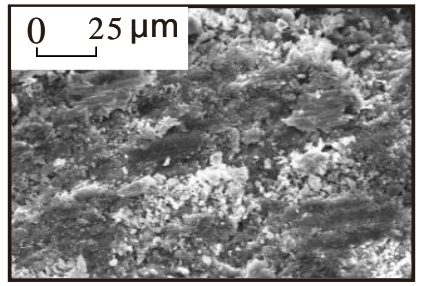

(a) 0 day

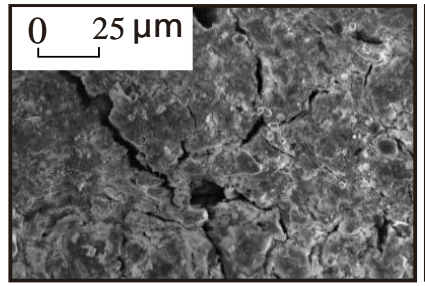

(b) 7 days

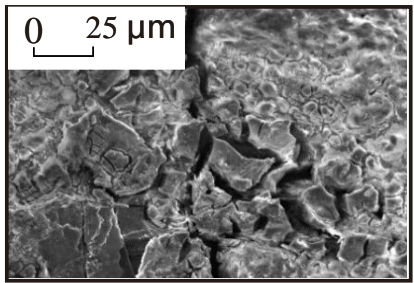

(c) 14 days

Fig.6. SEM analysis of the samples with different durations of acid rain action.

Figure 6 shows that the cracks gradually grew and propagated with increased exposure to acid rain, probably because some of the clay minerals and soluble salts were dissolved in acid rain and then carried out with the solution. The cracks that formed are inferred to have accelerated the reduction of strength.

\section{Conclusions}

Experiments were performed to analyze the interaction between acid rain and gabbro. Based on the results of direct shear tests, it can be seen that the shear strength of samples decreased with increased acid rain exposure time, and the specific mechanism of this strength reduction is explained by two aspects of microscopic analysis:

1) Part of the chain silicate mineral (pyroxene) and the framework silicate mineral (calcic plagioclase) were converted into layered silicate minerals (chlorite, illite and kaolinite) under acidic conditions, leading to a decrease of shear strength;

2) With soluble salts and some clay minerals being gradually dissolved and removed by acid rain, cracks gradually propagate in the samples. Newly formed cracks leading to less effective shear area probably also accelerates the reduction of strength.

Acknowledgements. The work was funded by the National Natural Science Foundation of China (No. 41672295), Science and Technology Project of Department of Transportation of Sichuan Province (No. 2015B1-1). The authors would like to extend their most sincere gratitude to the Editors and Reviewers who provide help during the writing of this paper.

\section{References}

1. M. Zhang, M.J. McSaveney, Earth Plan. Sci. Lett, 481, 284-289 (2018)

2. V. Gupta, I. Ahmed, Eng. Geol., 95, 79-87 (2007)

3. M. Taghipour, M. Nikudel, M. Farhadian, Bull. Eng. Geol. Environ., 75,967-978 (2016)

4. M. Chigira, W. Wang, T. Furuya, T. Kamai, Eng. Geol. 68, 259-273 (2003)

5. S. Goldich, J. Geol., 46, 17-58 (1938) 